\title{
Diffuse reduction of cerebral grey matter volumes in Erdheim-Chester disease
}

\author{
Eli L. Diamond ${ }^{1 *}$, Vaios Hatzoglou ${ }^{2}$, Sneha Patel ${ }^{3}$, Omar Abdel-Wahab ${ }^{4}$, Raajit Rampal ${ }^{4}$, David M. Hyman ${ }^{4}$, \\ Andrei I. Holodny ${ }^{2}$ and Ashish Raj ${ }^{3}$
}

\begin{abstract}
Background: Erdheim-Chester disease (ECD) is a rare non-Langerhans histiocytosis characterized by systemic inflammation and granulomatous infiltration of multiple organs including the central nervous system (CNS), bones, and retroperitoneum. CNS infiltration occurs in one third of patients, but cognitive changes are common in patients without CNS disease. Here we investigate whether there is a neuroanatomic basis to observed cognitive deficits, even in absence of CNS disease.
\end{abstract}

Methods: We present a volumetric analysis of eleven ECD patients without CNS tumors or prior neurotoxic treatments. Results: Compared to age-matched controls, ECD patients have diffuse, bihemispheric reduction in cortical thickness and subcortical gray matter.

Conclusions: These findings provide the first corroborating evidence for neurologic disease in ECD patients without direct CNS infiltration.

Keywords: Histiocytosis, Erdheim-Chester disease, Brain, MRI

\section{Background}

Erdheim-Chester disease (ECD) is a rare non-Langerhans histiocytosis reported in approximately 550 cases since its initial description in 1930. ECD is a multisystem disease characterized by lipogranulomatous histiocytic infiltration in virtually any organ, although the most commonly affected sites include the bones of the legs, retroperitoneum, heart, orbits, skin, and brain [1]. Historically, ECD was postulated to be an autoimmune-granulomatous disorder characterized by chronic inflammation and cytokine perturbations [2]; recently it has been recognized as an inflammatory myeloid neoplasia associated with oncogenic mutations of kinase signaling including $B R A F, N R A S$, KRAS, MAP2K1, and PIK3CA [1, 3, 4].

Histiocytic infiltrates of the brain or surrounding structures occur in one-third of patients and central nervous system (CNS) involvement is a chief cause of death in ECD [1]. However, neurologic symptoms and signs, including cognitive decline and behavioral changes, have

\footnotetext{
* Correspondence: diamone1@mskcc.org

${ }^{1}$ Department of Neurology, Memorial Sloan Kettering Cancer Center, 160 E.

53rd. St. Second Floor Neurology, New York, NY 10022, USA

Full list of author information is available at the end of the article
}

been informally observed in ECD patients without evidence of infiltrative tumors in the brain. These phenomena are of pressing significance to patients but have yet to be characterized clinically or radiographically. As a first attempt to describe neuroanatomical abnormalities in ECD unrelated to neoplastic infiltration, we performed exploratory whole-brain cortical thickness analysis of eleven ECD patients without cerebral CNS lesions or prior cytotoxic chemotherapies and compared them to age-matched controls. Our hypothesis was that there would be reduced cortical thickness in ECD as compared to controls.

\section{Methods}

Eleven patients with histologically confirmed ECD were studied. To eliminate confounding effects of disease or treatment, patients had neither (1) supratentorial lesions on T2-weighted/FLAIR or T1-weighted MRI nor (2) prior cytotoxic chemotherapy. All patients had high-resolution 3D-volumetric T1-weighted gadolinium-enhanced scans performed for standard clinical evaluation. These images were performed on $1.5 \mathrm{~T}$ or $3 \mathrm{~T}$ scanners (Signa HDxt/ Excite, Discovery 450/750, GE Healthcare) using an 8channel head coil with slice thickness ranging from 1 to 
$2 \mathrm{~mm}$, in plane resolutions ranging from 0.55 to $1.26 \mathrm{~mm}^{2}$ and voxel volumes ranging from 0.74 to $2.04 \mathrm{~mm}^{3}$. Images were analyzed with the FreeSurfer (http://freesurfer.net) semi-automated processing pipeline $[5,6]$. Images were morphed to Talairach space, white matter intensities were normalized, and the brain portion was extracted by skull-stripping. Because of gadolinium enhancement of the dura and choroid, a custom preprocessing pipeline involving a custom brain mask was developed and added to Freesurfer [7]. SPM's DARTEL tool was used for a more robust classification of the brain into six tissue types: gray matter, white matter, cerebrospinal fluid, skull, soft non-brain tissue, and air. FSL and AFNI were used to combine these tissue maps and to dilate them to remove hyperintense dura and choroid. This augmented brain mask was then entered into Freesurfer and subsequent steps followed the automated processing stream. An experienced board-certified neuroradiologist inspected and approved all segmentations. Three patients were excluded because of inadequate segmentation. For the purpose of obtaining statistical parameter maps, 14 healthy age-matched subjects' MRIs were chosen from an ongoing volumetric study of healthy subjects. Acquisition and processing protocols were identical to the ECD group, save that these had fully standardized image acquisitions and did not require custom pre-processing. Group-level whole-brain comparison of cortical thickness and subcortical volumes were performed in the ECD patients and controls. Significance of identified clusters was thresholded at $p<0.001$ after correction for multiple comparisons with the false discovery rate (FDR) method.

\section{Results}

Seven patients were men and age ranged 48-75 (Table 1). Sites of disease involvement for the entire cohort includes bones, retroperitoneum, mesentery, orbits, subcutaneous and spinal soft tissues, lungs, heart, skin, and posterior fossa. Seven patients had cognitive complaints of inattention or memory difficulties and described compromised performance at work or inability to work entirely. Cerebrospinal fluid was obtained and unremarkable in five patients. Non-specific inflammatory markers were elevated in all patients tested. 10/11 patients had had no ECD treatment, and one was treated with immunosuppression.

Comparison of cortical thickness between ECD patients and age-matched controls revealed diffuse bihemispheric reduction in cortical thickness (Fig. 1). Analyses were performed including and excluding the two patients with infratentorial disease with entirely comparable results; therefore, the findings of all 11 patients are presented. After FDR correction, 37 clusters were significant at $p<0.001,21$ in the left hemisphere and 16 in the right (Table 2). Of these, 17 were in parietal cortices (9 left, 8 right), 10 were in frontal cortices (6 left, 4 right), 6

Table 1 Patient characteristics

\begin{tabular}{|c|c|c|c|c|c|c|}
\hline Patient & Organ systems affected by ECD & Co-morbid illnesses & $\begin{array}{l}\text { Cognitive } \\
\text { complaints }\end{array}$ & $\begin{array}{l}\text { Concurrent } \\
\text { Medications }\end{array}$ & $\begin{array}{l}\text { Inflammatory } \\
\text { Markers }^{a}\end{array}$ & CSF Examination $^{b}$ \\
\hline \multirow[t]{2}{*}{66 Female } & \multirow[t]{2}{*}{ Myocardium, bones } & \multirow[t]{2}{*}{ None } & \multirow[t]{2}{*}{ No } & \multirow[t]{2}{*}{ None } & $E S R>100$ & \multirow{2}{*}{$\begin{array}{l}1 \text { WBC; Protein 28; } \\
\text { Glucose 57; }\end{array}$} \\
\hline & & & & & CRP 4.39 & \\
\hline 75 Male & Mesentery, orbit, bones, skin & $\begin{array}{l}\text { Chronic myelomonocytic } \\
\text { leukemia }\end{array}$ & Yes & Prednisone & CRP 0.98 & - \\
\hline \multirow[t]{2}{*}{54 Male } & \multirow{2}{*}{$\begin{array}{l}\text { Brainstem, retroperitoneum, } \\
\text { bones }\end{array}$} & \multirow[t]{2}{*}{ Diabetes mellitus } & \multirow[t]{2}{*}{ No } & \multirow[t]{2}{*}{ Prednisolone } & ESR 31 & \multirow{2}{*}{$\begin{array}{l}2 \text { WBC; Protein 42; } \\
\text { Glucose } 78\end{array}$} \\
\hline & & & & & CRP 1.8 & \\
\hline 51 Male & $\begin{array}{l}\text { Retroperitoneum, aorta, } \\
\text { pericardium, pleura, bones }\end{array}$ & Essential thrombocytosis & Yes & $\begin{array}{l}\text { Interferon-alpha, } \\
\text { anakinra }\end{array}$ & - & $\begin{array}{l}1 \text { WBC; Protein 21; } \\
\text { Glucose } 54\end{array}$ \\
\hline 51 Male & $\begin{array}{l}\text { Orbit, retroperitoneum, } \\
\text { epidural soft tissues, bones }\end{array}$ & Ulcerative colitis & Yes & None & CRP 1.63 & - \\
\hline \multirow[t]{2}{*}{60 Male } & \multirow{2}{*}{$\begin{array}{l}\text { Retroperitoneum, lung, skin, } \\
\text { bones }\end{array}$} & \multirow[t]{2}{*}{ MALT Iymphoma } & \multirow[t]{2}{*}{ Yes } & \multirow[t]{2}{*}{ Prednisone } & ESR 92 & \multirow{2}{*}{$\begin{array}{l}2 \text { WBC; Protein 33; } \\
\text { Glucose } 58\end{array}$} \\
\hline & & & & & CRP 1.49 & \\
\hline 48 Female & Orbit, retroperitoneum, bones & None & Yes & Prednisone & CRP 3.81 & - \\
\hline 66 Female & $\begin{array}{l}\text { Brainstem, retroperitoneum, } \\
\text { bones }\end{array}$ & None & Yes & Prednisone & - & $\begin{array}{l}2 \text { WBC; Protein 71; } \\
\text { Glucose } 57\end{array}$ \\
\hline \multirow[t]{2}{*}{68 Male } & \multirow{2}{*}{$\begin{array}{l}\text { Retroperitoneum, bones, } \\
\text { subcutaneous soft tissues }\end{array}$} & \multirow[t]{2}{*}{ None } & \multirow[t]{2}{*}{ No } & \multirow[t]{2}{*}{ None } & ESR 61 & \multirow[t]{2}{*}{-} \\
\hline & & & & & CRP 6.29 & \\
\hline 58 Male & Orbit, retroperitoneum, bones & None & No & Prednisone & CRP 3.42 & - \\
\hline 52 Female & $\begin{array}{l}\text { Subcutaneous soft tissues, } \\
\text { maxillary sinus, bones, skin }\end{array}$ & None & Yes & None & CRP 2.56 & - \\
\hline
\end{tabular}

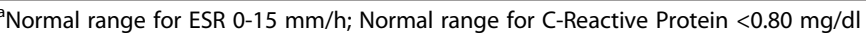

${ }^{\mathrm{b}}$ Normal WBC count in CSF <4 cells per $\mu \mathrm{L}$; Normal CSF protein $21-38 \mathrm{mg} / \mathrm{dL}$; Normal CSF glucose $38-82 \mathrm{mg} / \mathrm{dL}$ 


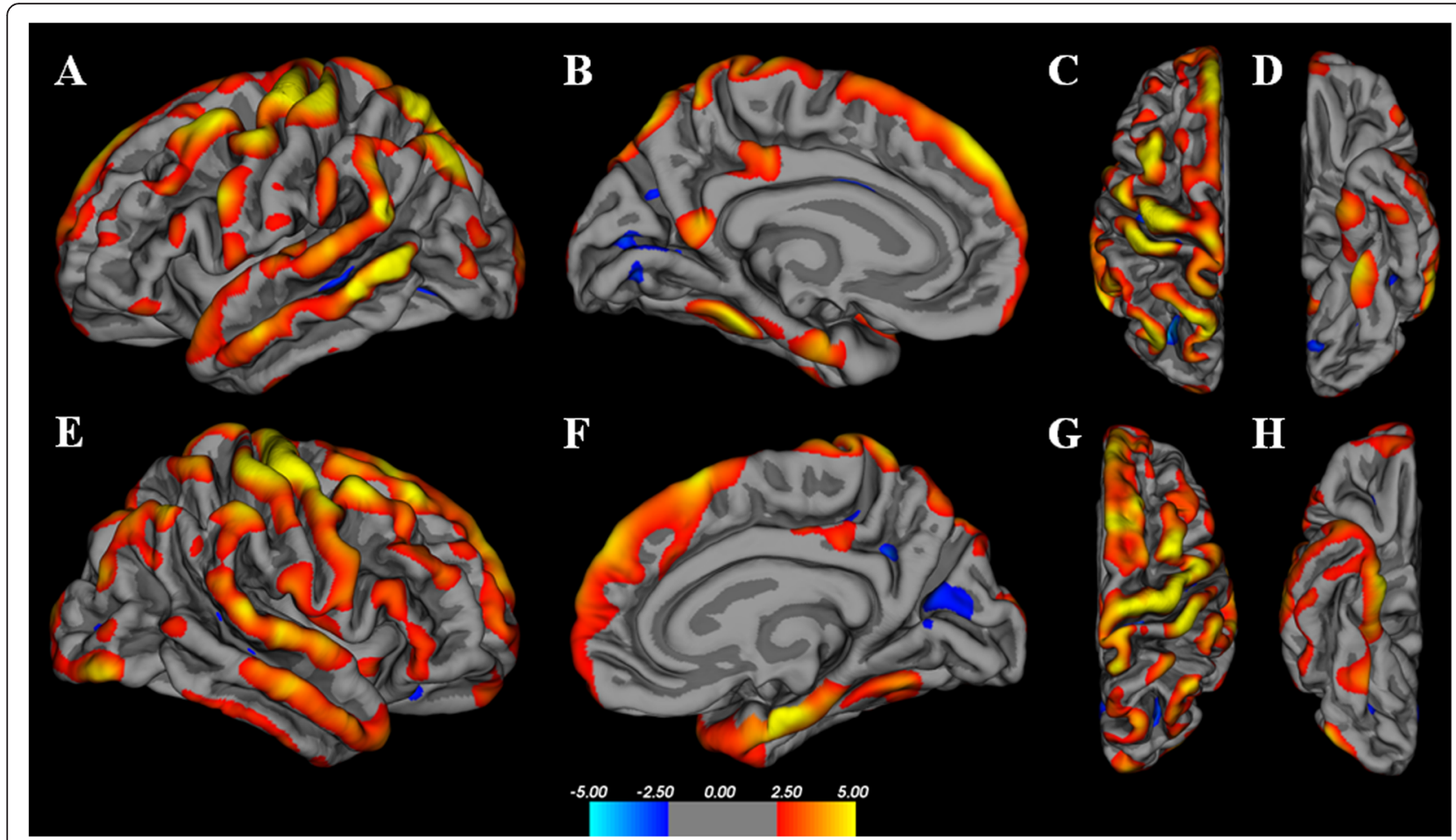

Fig. 1 Whole-brain cortical thickness analysis of 11 ECD patients as compared to age-matched controls. Color maps represent statistical significance (t-statistic), with yellow representing the greatest statistical significance. Both cerebral hemispheres are represented in lateral projections $(\mathbf{a}, \mathbf{e})$, medial projections $(\mathbf{b}, \mathbf{f})$, superior $(\mathbf{c}, \mathbf{g})$, and inferior $(\mathbf{d}, \mathbf{h})$. The maps demonstrate diffuse and widespread regions of cortical volume loss with a predominance of the frontal and temporal lobes

were in temporal cortices (3 left, 3 right), and 4 were in occipital cortices (3 left, 1 right). The largest clusters (greater than $10 \mathrm{~cm}^{2}$ surface area on the Desikan-Killarney standard brain atlas) were in the right precentral gyrus $\left(38.32 \mathrm{~cm}^{2}\right)$, right superior frontal gyrus $\left(38.56 \mathrm{~cm}^{2}\right)$, left supramarginal gyrus $\left(33.59 \mathrm{~cm}^{2}\right)$, left superior frontal gyrus $\left(19.86 \mathrm{~cm}^{2}\right)$, left precentral gyrus $\left(19.42 \mathrm{~cm}^{2}\right)$, right entorhinal cortex $\left(16.62 \mathrm{~cm}^{2}\right)$, and left superior parietal gyrus $\left(10.52 \mathrm{~cm}^{2}\right)$. Total subcortical grey matter volume was significantly reduced in ECD patients (mean volume $\left.57 \mathrm{~cm}^{3} \pm 5.1\right)$ compared to controls $\left(158 \mathrm{~cm}^{3} \pm 21.6 ; p<\right.$ 0.0001 ; Table 2). There were no differences in white matter or cerebellar volumes between patients and controls.

\section{Discussion}

In this study we present group-level analysis of cortical thickness and subcortical volumes in 11 ECD patients compared to age-matched healthy controls. Despite the small number of patients, reduction of cortical thickness and subcortical grey matter volumes in ECD patients was demonstrated to a statistical significance of $p<0.001$ in 37 cortical clusters after correction for multiple comparisons. These findings suggest the possibility of a diffuse and significant neurodegenerative process at hand. This study provides the first objective evidence to corroborate a common clinical observation of neurologic dysfunction in ECD patients without cerebral tumors. Further confirmation and characterization of this process in its relation to ECD is vital not only to envision potential interventions but also to advocate for appropriate medical and disability benefits.

Neuropathologic studies of ECD are sparse and describe mass lesions whose histopathology reveals classic histiocytic infiltrates with admixed inflammation [8]. No pathologic studies of brains ostensibly unaffected by ECD have been performed. There is greater literature about neurologic and neuropathologic findings in Langerhans cell histiocytosis (LCH), an entity closely related to ECD. Non-infiltrative neurodegenerative phenomena are recognized in pediatric $\mathrm{LCH}$, although rare. The spectrum of findings includes T2 abnormalities in the cerebellum, cerebellar degeneration, supratentorial leukoencephalopathy, dilation of Virchow-Robin spaces, and rarely diffuse cerebral atrophy [9]. Subclinical neurocognitive deficits have been found in a minority of long-term LCH survivors, although without correlation to neuropathologic findings, and it remains unclear whether these are sequelae of disease or treatment [10]. Mechanisms underlying noninfiltrative disease in $\mathrm{LCH}$ have not been identified, although paraneoplasia has been postulated and modest 
Table 2 Comparison of cortical thickness and subcortical volumes between ECD Patients and age-matched controls

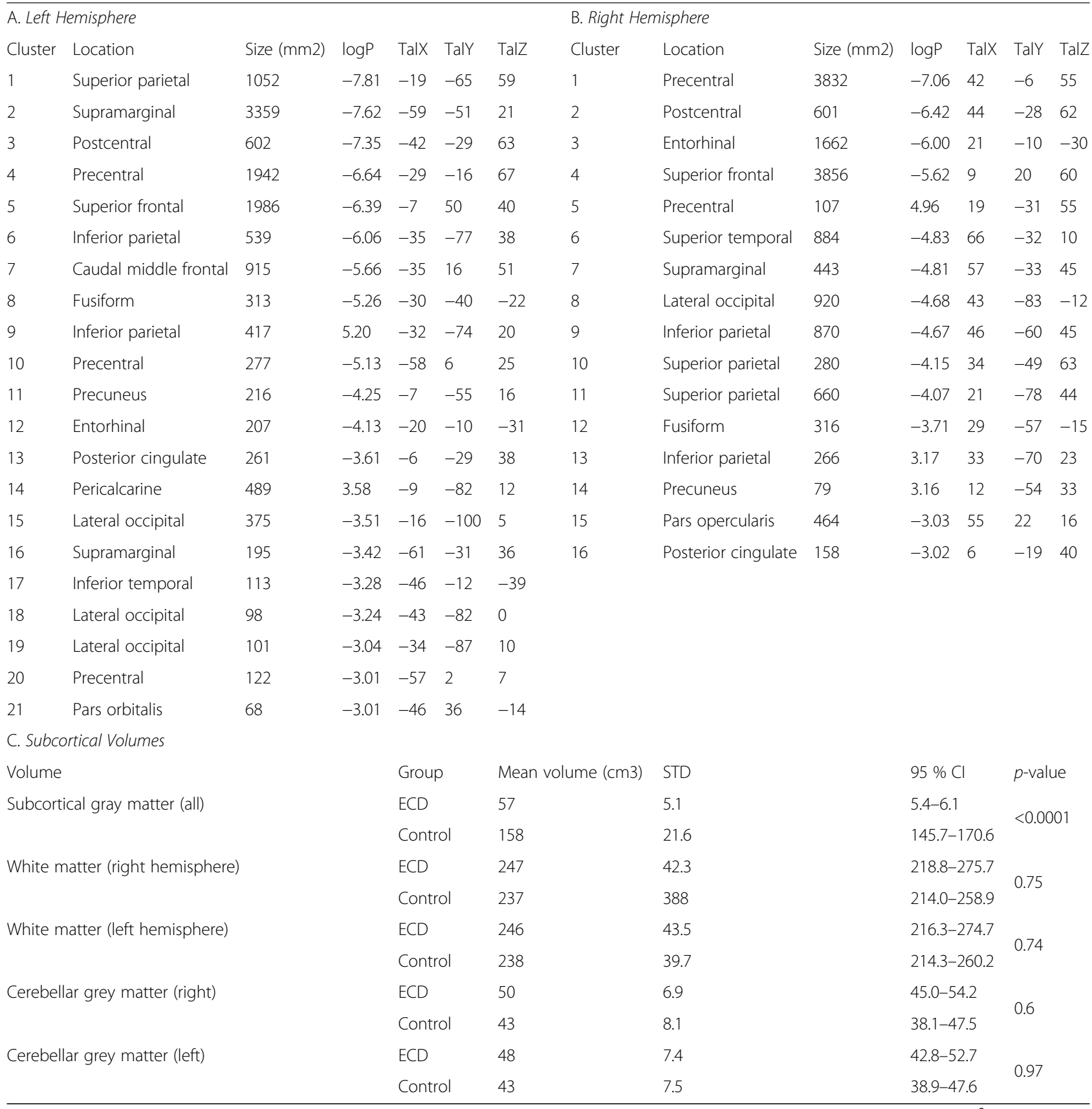

Significant clusters with FDR corrected $p<0.001$ are listed in order of descending statistical significance with anatomic location, cluster size in mm ${ }^{2}$, log(10)P, and Talairach coordinates for the cortical regions of the left (A) and right (B) hemispheres. Comparison of subcortical volumes, including total white matter, total grey matter, and total cerebellar volumes, is presented in (C)

therapeutic benefit has been seen with immunosuppressive and cytotoxic therapies [9].

Further study is necessary to suggest a mechanism for reduction in cerebral volumes in ECD. Our study does not establish whether this phenomenon is restricted to grey matter, as we did not examine the white matter in a dedicated fashion. It is possible that reduction in grey matter is secondary to a primary process involving the white matter, such as has been postulated in subcortical dementias [11, 12]; in our patients there is no visible leukoencephalopathy, but inapparent white matter dysfunction is possible. Also, it is worth noting that the diffuse pattern of grey matter loss is different from that seen with other neurodegenerative entities, such as Alzheimer's disease, Lewy body dementia, and HIV-associated neurodegeneration, which have various regional distributions [13-15]. Because ECD can be diagnosed years and even 
decades after first symptoms, the possible chronicity of disease in these patients suggests that grey matter changes may have been more regional and less diffuse if measured earlier. Prospective and longitudinal study of this nature in ECD patients would be extremely informative.

A defining feature of ECD is robust, chronic, and uncontrolled systemic inflammation. Because of its extreme rarity, ECD is frequently diagnosed after several years of symptoms, and therefore inflammation is longstanding even in newly diagnosed patients. Studies have described a signature pattern of cytokine perturbations in ECD, including elevations in TNF- $\alpha$, IL- $1 \beta$, and IL- 6 , and it has been shown that a cytokinemic state persists even in the setting of treated disease [2, 16-18]. Systemic inflammation itself has been implicated as a cause of neurotoxicity and neurodegeneration [19-21], and it is plausible that such a process is operative in ECD. One potential pathogenic mechanism involves cytokines that readily pass the blood-brain barrier, activate microglia, and perpetuate further maladaptive inflammatory events [19]. It is notable that the cytokines imputed in this process, TNF- $\alpha$, IL- $1 \beta$, and IL- 6 , are specifically those elevated in ECD. Cytokine studies of CSF have not been performed to corroborate this idea or to provide any evidence of neuroinflammation in ECD.

There are several limitations to this exploratory study. First, our cohort is small. Furthermore, there are no neurocognitive data to quantitate cognitive complaints or to identify subclinical deficits. The ulta-rarity of this orphan disease, however, renders it uniquely difficult to collect data prospectively. In light of this, a sample of 11 evaluable high-resolution images of patients without confounding treatments represents a relatively large cohort without precedent. Regarding image processing, scans were obtained for clinical care, and therefore there was variability in acquisition parameters and magnet strength. For that reason, scans were carefully screened and removed if segmentation quality precluded accurate volumetrics. Furthermore, cortical thickness measurement by Freesurfer has demonstrated consistency across scanning platforms and field strengths [22]. In addition, the uniformity of our findings and their statistical strength suggests they will be reproduced in larger studies. Finally, it should be noted that several patients were taking corticosteroids, and this has been independently found to be associated with brain atrophy by a variety of possible mechanisms including osmotic effects [23]. This finding has been observed mainly in the context of high-dose steroids or long-term low-dose steroids, neither of which was administered to our patients. Confirmation of these findings in a prospective study with parallel analysis of complementary imaging modalities, assessment of cognitive function, and correlation with markers of serum and CSF inflammation is necessary.

\section{Abbreviations}

CNS, central nervous system; CRP, C-reactive protein; CSF, cerebrospinal fluid; ECD, Erdheim-Chester Disease; ESR, Erythrocyte sedimentation rate; FDR, False discovery rate; $\mathrm{MRI}$, magnetic resonance imaging

\section{Acknowledgements}

Many thanks to Kathleen Brewer and the patients and families of the Erdheim-Chester Disease Global Alliance.

\section{Funding}

Funding for this study was provided by the Geoffrey Beene Research Center and by the Erdheim-Chester Disease Global Alliance.

\section{Availability of data and supporting materials}

Raw data (participants' MRI images) cannot be made available per IRB policies.

\section{Authors' contributions}

$E L D, V H, A I H, A R$, and SP contributed to study conception and design. ELD, $\mathrm{VH}, \mathrm{OAW}, \mathrm{RR}, \mathrm{DMH}, \mathrm{AlH}, \mathrm{AR}$ and SP contributed to the acquisition and analysis and interpretation of data. ELD, VH, OAW, RR, DMH, AlH, and AR contributed to the drafting and revision of the manuscript and figures. All authors read and approved the final manuscript.

\section{Competing interests}

Dr. Diamond has no conflicts to disclose.

Dr. Hatzoglou has no conflicts to disclose.

Ms. Patel has no conflicts to disclose.

Dr. Abdel-Wahab has no conflicts to disclose.

Dr. Rampal has no conflicts to disclose.

Dr. Hyman has no conflicts to disclose.

Dr. Holodny has no conflicts to disclose.

Dr. Raj has no conflicts to disclose.

\section{Consent for publication}

Not applicable as no individual person's data is presented in this report. The brain image presented in the figure is model projection of a standardized brain surface and does not belong to any individual.

\section{Ethics approval and consent to participate}

All study procedures were approved the Institutional Review Boards of both Memorial Sloan Kettering Cancer Center and Weill Cornell Medical College. A waiver of consent was issued (WA0072-13) as this data was analyzed retrospectively.

\section{Author details}

${ }^{1}$ Department of Neurology, Memorial Sloan Kettering Cancer Center, 160 E. 53rd. St. Second Floor Neurology, New York, NY 10022, USA. ${ }^{2}$ Department of Radiology, Memorial Sloan Kettering Cancer Center, New York, USA.

${ }^{3}$ Department of Radiology, Well Cornell Medical College, New York, USA. ${ }^{4}$ Human Oncology and Pathogenesis Program, Department of Medicine, Memorial Sloan Kettering CancerCenter, New York, USA.

Received: 14 March 2016 Accepted: 26 July 2016

Published online: 02 August 2016

\section{References}

1. Diamond EL, Dagna L, Hyman DM, et al. Consensus guidelines for the diagnosis and clinical management of Erdheim-Chester disease. Blood. 2014;124(4):483-92.

2. Arnaud L, Gorochov G, Charlotte F, et al. Systemic perturbation of cytokine and chemokine networks in Erdheim-Chester disease: a single-center series of 37 patients. Blood. 2011;117(10):2783-90.

3. Haroche J, Cohen-Aubart F, Charlotte F, et al. The histiocytosis Erdheim-Chester disease is an inflammatory myeloid neoplasm. Expert Rev Clin Immunol. 2015;21:1-10.

4. Diamond EL, Durham BH, Haroche J, et al. Diverse and targetable kinase alterations drive histiocytic neoplasms. Cancer Discov. 2016;6(2):154-65.

5. Dale AM, Fischl B, Sereno MI. Cortical surface-based analysis. I. Segmentation and surface reconstruction. Neuroimage. 1999;9(2):179-94.

6. Fischl B, Sereno MI, Dale AM. Cortical surface-based analysis. II: Inflation, flattening, and a surface-based coordinate system. Neuroimage. 1999;9(2):195-207. 
7. Napadow V, Dhond R, Kennedy D, Hui KK, Makris N. Automated brainstem co-registration (ABC) for MRI. Neuroimage. 2006;32(3):1113-9.

8. Adle-Biassette H, Chetritt J, Bergemer-Fouquet AM, Wechsler J, Mussini JM, Gray F. Pathology of the central nervous system in Chester-Erdheim disease: report of three cases. J Neuropathol Exp Neurol. 1997;56(11):1207-16.

9. Grois N, Fahrner B, Arceci RJ, et al. Central nervous system disease in Langerhans cell histiocytosis. J Pediatr. 2010;156(6):873-81. 81 e1.

10. Mittheisz E, Seidl R, Prayer D, et al. Central nervous system-related permanent consequences in patients with Langerhans cell histiocytosis. Pediatr Blood Cancer. 2007:48(1):50-6.

11. Kim CH, Seo SW, Kim GH, et al. Cortical thinning in subcortical vascular dementia with negative 11C-PiB PET. J Alzheimer's Dis. 2012;31(2):315-23.

12. Seo SW, Lee JM, Im K, et al. Cortical thinning related to periventricular and deep white matter hyperintensities. Neurobiol Aging. 2012;33(7):1156-67.

13. Gispert JD, Rami L, Sanchez-Benavides G, et al. Nonlinear cerebral atrophy patterns across the Alzheimer's disease continuum: impact of APOE4 genotype. Neurobiol Aging. 2015;36(10):2687-701.

14. Aylward EH, Brettschneider PD, McArthur JC, et al. Magnetic resonance imaging measurement of gray matter volume reductions in HIV dementia. Am J Psychiatry. 1995;152(7):987-94.

15. Sanchez-Castaneda C, Rene R, Ramirez-Ruiz B, et al. Correlations between gray matter reductions and cognitive deficits in dementia with Lewy Bodies and Parkinson's disease with dementia. Mov Disord. 2009;24(12):1740-6.

16. Stoppacciaro A, Ferrarini M, Salmaggi C, et al. Immunohistochemical evidence of a cytokine and chemokine network in three patients with Erdheim-Chester disease: implications for pathogenesis. Arthritis Rheum. 2006;54(12):4018-22.

17. Dagna L, Corti A, Langheim S, et al. Tumor necrosis factor alpha as a master regulator of inflammation in Erdheim-Chester disease: rationale for the treatment of patients with infliximab. J Clin Oncol. 2012;30(28):e286-90.

18. Ferrero E, Belloni D, Corti A, Doglioni C, Dagna L, Ferrarini M. TNF-alpha in Erdheim-Chester disease pericardial effusion promotes endothelial leakage in vitro and is neutralized by infliximab. Rheumatology. 2014;53(1):198-200.

19. Perry VH. Contribution of systemic inflammation to chronic neurodegeneration. Acta Neuropathol. 2010;120(3):277-86.

20. Lee BN, Dantzer R, Langley KE, et al. A cytokine-based neuroimmunologic mechanism of cancer-related symptoms. Neuroimmunomodulation. 2004;11(5):279-92.

21. Dantzer R, O'Connor JC, Freund GG, Johnson RW, Kelley KW. From inflammation to sickness and depression: when the immune system subjugates the brain. Nat Rev Neurosci. 2008;9(1):46-56.

22. Han X, Jovicich J, Salat D, et al. Reliability of MRI-derived measurements of human cerebral cortical thickness: the effects of field strength, scanner upgrade and manufacturer. Neuroimage. 2006;32(1):180-94.

23. Zivadinov R. Steroids and brain atrophy in multiple sclerosis. J Neurol Sci. 2005;233(1-2):73-81.

\section{Submit your next manuscript to BioMed Central and we will help you at every step:}

- We accept pre-submission inquiries

- Our selector tool helps you to find the most relevant journal

- We provide round the clock customer support

- Convenient online submission

- Thorough peer review

- Inclusion in PubMed and all major indexing services

- Maximum visibility for your research

Submit your manuscript at www.biomedcentral.com/submit

C Biomed Central 